\title{
INFANTILE SCURVY FOLLOWING THE USE OF RAW CERTIFIED MILK*
}

\author{
HAROLD K. FABER, M.D. \\ SAN FRANCISCO
}

From the fact that most textbooks on diseases of children state that scurvy may occur on a diet of raw milk, the extreme rarity of the occurrence is, perhaps, not sufficiently appreciated. The only direct references to such cases that I have been able to find are in the classic report of the American Pediatric Society ${ }^{1}$ and in a paper by Dr. J. L. Morse. ${ }^{2}$ The first of these authorities, under the heading "Food used at or shortly before scurvy developed," states: "Raw milk alone, 4; with breast milk and amylaceae, 1; total 5." No further details of the cases are furnished. The total number of cases in this report in which the character of the food is specified, is 356 . Morse's report, embracing fifty-eight cases, includes one case on raw milk, but the length of time it had been administered and other details are not given. It is a curious fact that many more cases of scurvy are reported in infants fed on breast milk than on cow's milk feeding; in the Ámerican Pediatric Society report there are ten, and in Morse's report, three breast milk cases.

The case reported herewith is apparently the first in which raw milk had been given practically from birth, and it has the additional value in more clearly defining the issue, that certified milk exclusively was employed.

\section{REPORT OF CASE}

History.-A girl, aged 10 months, was admitted to the Children's Clinic of Leland Stanford Junior University Medical School, Oct. 28, 1919. Complaint: "rheumatism." Father and mother are healthy, young American born people of Italian parentage, with no history or indicaton of syphilis or other disease. The patient is the first-born. There have been no previous pregnancies.

The baby was born at full term weighing 6 pounds, 7 ounces. She was never breast fed but from the first has been given on physician's advice a formula consisting of raw certified milk, Mead's dextrimaltose No. 1 and boiled water, with the addition to each bottle of the following preparation: Sodium citrate, 3 drams; distilled water, 2 ounces. Ten drops have been added to each feeding.

The formula was at first made up of one part of milk and two parts of water; at about 2 months it was changed to a half-and-half mixture, and at 9 months, to a two-thirds mixture. A teaspoonful of dextrimaltose was added to each bottle. Seven bottles a day, at three hour intervals, were given until the baby was 9 months old, since then three bottles a day have been given.

* Received for publication, Dec. 14, 1920.

* From the Subdivision of Pediatrics, Stanford University Medical School.

1. The American Pediatric Society's Collective Investigation on Infantile Scurvy in North America, Tr. Am. Pediat. Soc. 10:5, 1898.

2. Morse, J. L.: Infantile Scorbutus, Boston M. \& S. J. 170:504, 1914. 
The mother states that she has always offered the baby 8 ounces of the milk mixture and allowed her to take as much of it as she would. Until the present illness began the baby made, apparently, satisfactory progress in weight and growth. Shortly after the symptoms. began, the diet was changed so that the infant received three bottles a day supplemented by farina, eggs, Italian pastes with a little olive oil, but no fresh vegetables, fruit or fruit juices have ever been given. Except for two days, when the baby was 6 months old, nothing but certified milk has been used. The mother was very emphatic on this point and brought a bottle of the milk to corroborate-as it did-her assertion. The formula has never been boiled or heated, except when it was warmed at feeding time. From the feeding history it would appear that the physician in giving the mother his instructions had kept in mind the dangers of scurvy from heated milk.

Present Illness. - The first symptoms were noticed by the mother about July 1, when the baby was 6 months old. In putting on the baby's stockings, the mother noticed that the left tibia was tender, and about a month later the baby cried when the shoes were put on. The tenderness increased slowly. About a month ago (toward the end of September) swelling and pain in the knees were noticed, and a week later the mother found one morning that the mouth was bloody. On investigation she saw that the blood was coming from the gums.

Questioned as to trauma, the mother stated that in August, when the child was lifted from a chair the left foot caught in one of the rungs and the baby cried for a moment. In September, the baby had "fever" for three days, and since then has seemed to be "sore all over," but suffers most when the napkins are changed or stockings are put on. A diagnosis of "rheumatism" was made by the physician, but the mother was not satisfied with this diagnosis.

Physical Examination.-The baby is pale and pasty looking and very irritable when handled. The face is full, but the body is not well padded. The legs are flexed with the thighs everted and are held motionless. There is no craniotabes nor bossing. There is slight seborrhea of the scalp. Seven teeth are fully erupted. The gums around all these, but especially around the upper incisors, are swollen, purplish in color and bleed readily when touched. There is slight beading of the ribs, and a shallow Harrison's groove. The abdomen is not protuberant. Heart and lungs are normal. The liver is palpable about $2 \mathrm{~cm}$. below the costal margin. The spleen is not palpable. The genitalia are somewhat inflamed. On the buttocks are a number of small nearly healed excoriations. The lymph nodes are not enlarged. The wrist epiphyses are moderately enlarged but not tender. The lower femoral epiphyses are much enlarged, and the soft tissues over them are thickened. The knees are acutely tender, and motion is evidently very painful. The ankles and lower tibiae are also somewhat swollen and tender to pressure. About the right malleolus there is a faint bluish discoloration suggestive of a deep ecchymosis.

Impression: Scurvy and slight rickets.

Laboratory Examination.-Nov. 3, 1919: Erythrocytes, 4,219,000; hemoglobin 75 per cent.; leukocytes, 12,300 ; polymorphonuclears, 55 per cent.; lymphocytes, 40 per cent.; large mononuclears, 3 per cent.; transitionals, 2 per cent. The red blood cells were normal in shape, size and coloring. No normoblasts, megaloblasts or malarial parasites were seen.

November 4: Wassermann negative.

Roentgen-Ray Examinations.-Oct. 31, 1919: "Examination shows thickening along the diaphysis sides of the epiphyseal lines of all the long bones of the legs and forearms; slight periostitis about the upper part of the right tibia; apparently slight posterior displacement of the epiphyses of both femora."

November 4: "Further examination of both knees shows evidence of posterior displacement of the epiphyses of both femora; thickening along the diaphysis side of the epiphyseal line, as previously reported." 
November 15: "Examination of both legs, for comparison, shows evidence of thickening along the diaphysis side of the epiphyseal lines of all the long bones; considerable periostitis along the shafts of the long bones."

November 25: "Examination of both legs, for comparison, shows decrease in the thickening about the epiphyseal lines; periostitis about the same as at last examination."

Treatment.- The child was put on a top milk mixture with additions to the diet of cooked cereals, vegetable purees, yolk of egg, baked potato and 4 ounces of orange juice daily. No medication was given.

Later Progress.-The improvement was so rapid that the child was discharged in nine days (November 6) from the hospital with instructions to the mother to bring the child to the clinic. In spite of the posterior displacement of the lower epiphyses of both femurs, the baby was moving both legs voluntarily by November 4 . The general appearance was greatly improved. The gums had resumed their normal color. The legs were still considerably enlarged at knee and ankle but were only slightly tender. Orange juice, 2 ounces a day, was continued. The child when last seen in the clinic, December 6 , was practically normal in appearance and had gained about a pound and a half in the month since her discharge from the hospital.

\section{COMMENT}

Clinically, this case was typical scurvy. The diagnosis was fully corroborated by roentgenogram and by the prompt and complete disappearance of symptoms without medication on a diet rich in antiscorbutic substances. Mild rickets was also undoubtedly present.

The principal interest of this case lies. in the clear and complete dietary history extending from birth to the time of the patient's discharge from the clinic. The parents were intelligent and apparently sure of their facts. That raw certified milk had been used continuously seems to be beyond question. The undoubted extreme rarity of scurvy in infants fed on raw cow's milk demands a discussion of the possible causes of scurvy in this infant.

Two explanations may be advanced, first, that the amount of milk taken was too small; second, that the antiscorbutic vitamin was partly or wholly destroyed by some other agent than heat.

The experimental work of Chick, Hume and Skelton ${ }^{3}$ explained certain discrepancies in the conclusions of previous investigations on the antiscorbutic vitamin content of raw cow's milk by showing that while this vitamin is present in cow's milk, its concentration is low. Guinea-pigs receiving less than 50 c.c. of cow's milk a day invariably developed scurvy. This observation has been confirmed by several workers. In a recent investigation ${ }^{4} \mathrm{I}$ found a somewhat higher concentration in raw milk produced near San Francisco but noted the invariable appearance of scurvy when less than 30 c.c. was fed. The

3. Chick, H.; Hume, E. M., and Skelton, R. F.: The Antiscorbutic Value of Cow's Milk, Biochem. J. 12:131, 1918.

4. Faber, H. K.: Sodium Citrate and Scurvy, Proc. Soc. Exper. Biol. \& Med. 17: 140 , 1920 . 
experimental evidence, therefore, goes to show that the occurrence of scurvy in man might be due to too low an intake of raw milk, as well as to the use of milk in which the vitamin had been destroyed by heat or by other agents.

In the present case, a dilute formula ( 1 part milk, 2 parts water) was used up to the age of 2 months, and thereafter the strength was only 1 part milk and 1 part water. The exact quantities taken daily are not known, but the mother stated that the baby, except when very young, usually finished a bottle of 8 ounces every three hours, a total of seven bottles daily. It appears likely, therefore, that between the ages of 2 and 9 months, the period during which scurvy developed, the baby must have taken an average of nearly 28 ounces of milk daily. Since an intake of this amount is not often exceeded by infants between the ages stated, and since scurvy so rarely occurs during feeding with raw milk, it seems unlikely, though perhaps not impossible, that a quantitative deficiency could have been responsible for the occurrence of scurvy in the present case.

The second possibility-that the antiscorbutic vitamin had been destroyed-remains to be considered. Aging of the milk can hardly be thought of, since the vigilant milk commission of the San Francisco County Medical Society demands prompt marketing of all milk which it certifies. The possibility that the sodium citrate, added to each bottle taken by the patient since the first week of life, may have had a deleterious effect on the antiscorbutic vitamin deserves consideration.

Alkalization has been proposed by Hess and Unger ${ }^{5}$ as one of the causes of destruction of vitamin. They state that even such small quantities of alkali as are contained in certain infant foods may be sufficient to destroy the antiscorbutic vitamin in milk. ${ }^{6}$

A determination of the effect of sodium citrate on the hydrogen-ion concentration of a sample of raw milk, done through the kindness of Dr. E. C. Dickson, showed that an addition to the amount of 0.25 per cent. lowered the $P_{H}$ from 6.45 to 6.50 ; of 0.5 per cent., to 6.95 ; and of 1 per cent., to 7.05. The addition of 10 drops of an 18 per cent. solution of sodium citrate to 8 ounces of whole milk-the approximate amounts in the present case-giving a strength of 0.05 per cent., would lower the acidity by considerably less than $\mathrm{P}_{\mathrm{H}} 0.05$; probably, as shown by the plotted curve, by less than $P_{H} 0.01$. Such an alteration of atidity should be regarded as probably insignificant.

5. Hess, A. F., and Unger, L. J.: The Deleterious Effect of the Alkalization of Infant's Food, J. A. M. A. 73:1353 (Nov. 1) 1919.

6. It is only fair to state that this assertion has been disputed by several competent clinicians. (See discussion following Hess and Unger's report.) Mead's dextri-maltose No. 1 is stated by the manufacturers to contain 2 per cent. added sodium chlorid, but it apparently contains no added alkali. 
In a series of experiments ${ }^{4}$ it was shown that additions of from 0.25 to 2 per cent. of sodium citrate to raw milk apparently reduced the antiscorbutic vitamin content, since. in eight out of nine guinea-pigs fed on citrated milk, scurvy developed, while in the control series of eight animals, fed on raw milk alone, scurvy developed in only two, both of which took an average of less than 34 c.c. of milk daily. None of the animals in the citrate series took less than 35 c.c. daily and the average of the citrate series was 41.8 c.c. as compared with an average of 40.7 c.c. for the controls. It should, however, be pointed out that none of the experimental animals received as little sodium citrate as was given to the human case here reported. In the latter the concentration of sodium citrate in the formula was approximately 0.05 per cent., or a total of about $0.84 \mathrm{gm}$. daily. The long period of continuous administration may, however, be considered. Knowing that the concentration of vitamins in cow's milk is low, that the concentration was reduced to one third for the first two months and to one half during the next seven months, may not the amount of added citrate have been sufficient to lower the vitamin concentration just below the scorbutic threshold?

Assuming this to have been the case, I do not feel that we have as yet sufficient evidence to attempt an analysis of the modus operandi of sodium citrate in injuring the antiscorbutic vitamin. The degree of alkalization it produced in the patient's food was probably negligible. Bosworth and Van Slyke's ${ }^{7}$ observation that sodium citrate forms in milk a soluble sodium paracaseinate would not appear relevant to the question of scurvy. Certainly, the citrate ion-present in large amounts in so many antiscorbutic foods-cannot be brought into discussion. Finally, in spite of the presence of a certain amount of positive evidence and in the absence of other apparent antiscorbutic factors, it is not certain that in the present case sodium citrate was actually at fault. It would, however, appear justifiable to regard sodium citrate in formula preparation with considerable distrust and to give preference to other substances, such as barley water, over the mineral salts when we wish to alter the coagulability of cow's milk.

SUMMARY

1. An infant fed almost from birth on modified raw certified milk, to which small amounts of sodium citrate were added, developed scurvy at the age of 6 months.

2. It is possible, but not proved, that sodium citrate may have partly destroyed the antiscorbutic vitamin.

3. The use of sodium citrate in infant feeding over long periods should be provisionally regarded as dangerous.

7. Bosworth, A. W., and Van Slyke, L. L.: Why Sodium Citrate Prevents Curdling of Milk by Rennin, Am. J. Dis. Child. 7:298 (March) 1914. 